\title{
Philosophiques
}

\section{Jean Grondin, Einführung in die philosophische Hermeneutik, Darmstadt, Wissenschaftliche Buchgesellschaft, 1991, 249 p.}

\section{Marc Imbeault}

Volume 21, numéro 1, printemps 1994

URI : https://id.erudit.org/iderudit/027266ar

DOI : https://doi.org/10.7202/027266ar

Aller au sommaire du numéro

Éditeur(s)

Société de philosophie du Québec

ISSN

0316-2923 (imprimé)

1492-1391 (numérique)

Découvrir la revue

Citer ce compte rendu

Imbeault, M. (1994). Compte rendu de [Jean Grondin, Einführung in die philosophische Hermeneutik, Darmstadt, Wissenschaftliche Buchgesellschaft, 1991, 249 p.] Philosophiques, 21(1), 272-273. https://doi.org/10.7202/027266ar d'utilisation que vous pouvez consulter en ligne.

https://apropos.erudit.org/fr/usagers/politique-dutilisation/ 


\section{Jean Grondin, Einführung in die philosophische Hermeneutik, Darmstadt, Wissenschaftliche Buchgesellschaft, 1991, 249 p.}

\section{par Marc Imbeault}

Ce livre de Jean Grondin est une excellente introduction aux problemes philosophiques qui caractérisent l'herméneutique. Le point d'ancrage du livre est l'œuvre de Gadamer. L'auteur souligne d'ailleurs, dans un avant-propos autobiographique, l'importance qu'il accorde au dialogue instauré avec celui-ci. 
Dans le corps du texte, ce dialogue est poursuivi à la faveur d'une histoire de l'herméneutique qui s'apparente à la phénoménologie de l'esprit de Hegel. chaque étape de celle-ci marque en effet un jalon de la progression de la «conscience herméneutique », jusqu'à prétendre couvrir, de nos jours, la totalité de la philosophie.

Une première partie, consacrée à la « préhistoire » de la discipline, s'attache à reconstruire les données du problème dans la tradition de l'exégèse biblique et littéraire; par exemple en tentant d'élucider le sens de l'interprétation allégorique dans l'œuvre de Philon d'Alexandrie. Préhistoire, car ces auteurs n'ont pas cherché à élaborer de théorie générale de la compréhension (même exclusivement littéraire ou biblique).

La deuxième partie traite des rapports entre l'herméneutique, la grammaire et la critique. Le contexte dans lequel apparait cette constellation de concepts est celui de la nouvelle philosophie, inaugurée par Descartes et Bacon, où la science occupe une place prépondérante. Science de la nature, mais aussi science de l'esprit : des savants comme Dannhauer et Chladenius proposeront un véritable projet d'herméneutique universelle en vue de faire de l'interprétation une véritable science.

La troisième partie est consacrée à l'herméneutique romantique, moment capital de la « phénoménologie herméneutique de l'esprit » de Grondin (l'expression est de moi). Le processus de la compréhension est thématisé pour lui-même sans référence à une syntaxe idéale comme dans les projets inspirés du rationalisme. Schleiermacher contribue à l'avènement de l'herméneutique, en ce sens qu'il met à jour l'universalité du problème herméneutique et, de ce fait, la nécessité de l'interprétation. Les sections suivantes, consacrées à Dilthey, Heidegger et Gadamer, marquent le passage du point de vue de la critique de la connaissance illustré par Dilthey, à celui de l'ontologie de la compréhension contemporaine. La dernière partie fait le point sur le débat actuel entre les différents courants de pensée qui s'inspirent de l'herméneutique philosophique, notamment chez Habermas et Derrida.

Très bien documenté, avec une bibliographie très étendue et un index, toujours concis, précis et synthétique, le livre de Jean Grondin est l'une des plus belles contributions des dix dernières années en herméneutique. Le seul reproche que l'on pourrait lui faire serait peut-être son adhésion inconditionnelle aux doctrines gadamériennes, et son attitude acritique face aux prétentions hégémoniques de l'herméneutique philosophique. Par exemple Grondin ne fait aucune mention de la critique, inspirée de Wittgenstein, de l'universalité du problème herméneutique, développée notamment par Jacques Bouveresse.

Collège militaire royal de Saint-Jean 